\title{
Directly Converting Fe-doped Metal-Organic Frameworks into Highly Active and Stable Fe-N-C Catalysts for Oxygen Reduction in Acid
}

\author{
Xiaojuan Wang, ${ }^{\mathrm{a}}$ Hanguang Zhang, ${ }^{\mathrm{b}}$ Honghong Lin, ${ }^{\mathrm{a}}$ Shiva Gupta, ${ }^{\mathrm{b}}$ Cheng Wang, ${ }^{\mathrm{c}}$ Zixu Tao, ${ }^{\mathrm{a}}$ \\ $\mathrm{He} \mathrm{Fu},{ }^{\mathrm{a}}$ Teng Wang, ${ }^{\mathrm{a}}$ Jie Zheng, ${ }^{*, \mathrm{a}}$ Gang Wu, ${ }^{*}$, and Xingguo $\mathrm{Li}^{\mathrm{a}}$ \\ ${ }^{a}$ College of Molecular and Chemical Engineering, Peking University, Beijing, China \\ ${ }^{\mathrm{b}}$ Department of Chemical and Biological Engineering, University at Buffalo, the State \\ University of New York, Buffalo, New York 14260, United States \\ ${ }^{c}$ Institute of Nuclear and New Energy Technologies, Tsinghua University, Beijing, China

\section{Corresponding Authors:}

Jie Zheng: zhengjie@pku.edu.cn and Gang Wu: gangwu@buffalo.edu

\begin{abstract}
Compared to extensively studied oxygen reduction reaction (ORR) catalysis in alkaline media, development of highly active and stable nonprecious metal catalysts (NPMCs) to replace Pt in acidic electrolytes remains grand challenges. Among currently studied catalysts, the $\mathrm{Fe}-\mathrm{N}-\mathrm{C}$ formulation holds the greatest promise for the ORR in acid. Here, we report a new highly active and stable Fe-N-C catalyst featured with well-dispersed atomic Fe in porous carbon matrix, which was prepared through one single thermal conversion from Fe-doped ZIF-8, a metal-organic framework (MOF) containing $\mathrm{Zn}^{2+}$ and well-defined Fe-N 4 coordination. Unlike other Fe-N-C catalyst preparation, no additional tedious post-treatments such as acid leaching and the second heating treatment are required in this work. Notably, an $\mathrm{O}_{2}$-free environment for preparing the $\mathrm{Fe}$ doped ZIF-8 precursor is found to be crucial for yielding uniform Fe distribution into highly porous $\mathrm{N}$-doped carbon matrix. The resulting new Fe-N-C catalyst exhibited exceptionally improved ORR
\end{abstract}


activity with a very high half-wave potential $(0.82 \mathrm{~V} v s$. RHE) and sufficient potential cycling stability in acid. Opposite to previous observation, the highly active Fe-N-C catalyst is in the absence of any graphitized nanocarbons, which would lead to a new discussion in the field for understanding the role of carbon during the ORR electrocatalysis.

Keywords: Metal-organic frameworks; energy conversion; electrocatalysis; oxygen reduction; nonprecious metal catalysts; fuel cells

\section{Introduction}

Commercialization of polymer electrolyte fuel cells (PEFCs) for transportation and other potential applications is largely hindered by their high cost and insufficient performance durability [1-3]. The substantial cost is due to the large amount of Pt-based catalysts used at the cathode to catalyze the oxygen reduction reaction (ORR), a sluggish electrochemical reaction [4-6]. Developing nonprecious metal catalysts (NPMCs) derived from earth abundant elements for the ORR, therefore, is of critical to address the cost issue in PEFCs [7-14]. Since the first discovery of ORR activity of the Co phthalocyanine complex in 1964 [11], the heat treated M-N-C (M=Fe or Co) ORR catalysts have been extensively studied $[10,15]$. Such catalysts are typically prepared via pyrolyzing a composite precursor containing iron or cobalt, nitrogen, and carbon at temperatures above $700^{\circ} \mathrm{C}$ to achieve high activity and a robust structure $[1,14,16-19]$. The speculated ORR active sites are associated with $\mathrm{N}$ coordinated metal structures $\left(\mathrm{MN}_{\mathrm{x}}\right)$ with average coordination number $x$ from 2 to 4 evidenced by X-ray absorption techniques or Mössbauer spectroscopy [20-22]. However, the nature of active site is still under debate in the field. Recently an electrocatalyst with an active site devoid of any direct nitrogen coordination to iron exhibits comparable performance to the best performing Fe-N-C catalysts in acidic media [23]. In-situ X-ray absorption spectroscopy combined microscopy indicated that iron are not directly involved in the oxygen reduction pathway and are 
embedded into nitrogen-doped carbon fibres. Instead, the reaction occurs primarily on the carbonnitrogen structure in the outer skin. Despite the controversial evidences, among studied nonprecious metal catalyst formulations, the Fe-N-C catalyst represents the best NPMC for the ORR in terms of the most promising activity and stability, particularly in acidic electrolyte [24,25].

Although great progress has been made in last decade, the significant gaps between the Fe-N$\mathrm{C}$ and Pt catalysts must be bridged for viable application in terms of their activity and durability especially in harsh acidic electrolyte [3] [6,26-30]. A key step to further enhance the performance of the Fe-N-C catalyst is to increase the density of the ORR active $\mathrm{FeN}_{\mathrm{x}}$ sites in a robust 3D architecture. Because the catalyst performance is associated with the density of the active sites and their local structural environments [31]. Previous work has indicated that simply raising the Fe concentration in precursors is not effective, as this will lead to aggregation of iron, thereby generating inactive iron compounds [3]. The reported Fe-N-C catalysts with good performance typically contain less than $10 \mathrm{wt} \% \mathrm{Fe}$, while inactive aggregated particles of iron species (e.g., metallic iron, oxides or carbide) remain visible in most cases $[1,3,6,10,15,16,32,33]$. Thus, it remains a grand challenge to uniformly dispersed active atomic iron into high-surface areas carbon matrix, rather than generating iron agglomerates. Most of currently studied Fe-N-C catalysts are prepared by pyrolyzing a composite that was mixed with iron salts, nitrogen-carbon precursors, and high-surface area supports, followed by a tedious acidic leaching and the second treatment [24]. This synthesis lead to a heterogeneous morphology without accurate control of local structures for active sites. Exploring a highly ordered and porous precursor is demanded to achieve uniform distribution of active sites into a porous architecture with significantly increased density of active sites [34]. Recently metal organic frameworks (MOFs), built by secondary building of units from metals and organic linkers with strong bonding, have received a lot of attentions since 
they possess permanent porosity, three-dimensional (3D) structure and diversity of metals and organic linkers. The structure of MOFs consists of ligands containing carbon and nitrogen atoms coordinating with metals to form ordered 3D porous crystals. These not only meet the requirements of $\mathrm{M}-\mathrm{N}-\mathrm{C}$ composition as templates but also provides ordered three dimensional porous structures. Additionally, the strong interaction among metal atoms and nitrogen atoms beneficial to generating more active sites and higher intrinsic catalytic active sites via carbonization. In 2010, Liu initiated the preparation of $\mathrm{Co} / \mathrm{Fe}-\mathrm{N}-\mathrm{C}$ catalysts derived from MOFs for ORR cathodes in PEFCs [35-38]. Their promising results started bringing attention to societies, which MOF can be a good carbon/nitrogen precursor used for such catalyst preparation. In 2011, Dodelet et al. [16] developed a new Fe-N-C catalyst through physical mixing of ZIF-8, a zeolitic imidazolate framework (ZIF) composed of $\mathrm{Zn}$ and 2-methylimidazole, with $\mathrm{N}$-chelating Fe compounds using ball milling followed by two annealing treatments using $\mathrm{Ar}$ and $\mathrm{NH}_{3}$, respectively. The advantage of using ZIF-8 was highlighted in that work. It was found that pyrolysis of ZIF-8 in inert atmosphere can yield highly porous $\mathrm{N}$-doped carbon as $\mathrm{Zn}$ is volatile at high temperature and can be eliminated during pyrolysis. The resulting catalyst generated a high power density in fuel cell tests due to significantly increased active site number and facilitated mass transport in the porous catalyst layer. However, the synthesis procedure is still complicated involved tedious ball milling and two-time heat treatments. In addition, Fe precursors is still mixed with MOF by a physical way, rather than well-controlled chemical doping.

In this work, we report a new synthesis method to prepare a highly active Fe-N-C catalyst featured by uniform Fe distribution at an atomic level. During the synthesis, for the first time, $\mathrm{Fe}$ was successfully doped into ZIF-8 (zeolitic imidazolate framworks-8) by partially replacing Zn ions. As a results, $\mathrm{Fe}(\mathrm{II})$ was uniformly distributed into the framework with well-defined $\mathrm{Fe}-\mathrm{N}_{4}$ 
coordination. The highly active and stable Fe-N-C catalyst was prepared by one-step thermal treatment of Fe-doped ZIF-8. No additional tedious post-treatments such as acid leaching and the second heating treatment is required. During the thermal treatments, nitrogen and iron containing ZIF-8 framework directly converts into N-doped carbon with uniform Fe distribution without any agglomerated iron particles. The zinc species is eliminated due to its high volatility, yielding a highly porous carbon morphology. Notably, the control of an $\mathrm{O}_{2}$-free environment for stabilizing $\mathrm{Fe}(\mathrm{II})$, rather than forming $\mathrm{Fe}(\mathrm{III})$, during the preparation of Fe-doped ZIF-8 precursor was found to be extremely crucial for generating uniform Fe distribution at atomic level. This strategy effectively prevents formation of inactive iron aggregates. The exceptionally improved ORR activity is benefited from the uniform Fe distribution into porous carbon, capable of providing maximum density of the ORR active Fe sites. The novel synthesis starts with homogeneous doping of Fe into ZIF-8, a zeolitic imidazolate framework (ZIF) composed of Zn and 2-methylimidazole, followed by a simple one-step heat treatment.

\section{Experimental details}

\subsection{Catalyst synthesis}

Fe-doped ZIF-8 nanocrystals were prepared by using a surfactant mediated growth method. Traditionally, the preparation of ZIF-8 crystals needs much excessive ligands in aqueous solution. Surfactant methods enable the control of particle size of the ZIF-8 and are also crucial to prevent the formation of alkaline salt of $\mathrm{Zn}\left(e . g . \mathrm{Zn}(\mathrm{OH}) \mathrm{NO}_{3}\right)$ in aqueous solution. The micelles formed by the two surfactants will protect the $\mathrm{Zn}^{2+}$ from attacking by $\mathrm{OH}-$ and allows the $\mathrm{Zn}^{2+}$ preferentially binding to 2-methyimidazole. Usually Span 80 and Tween 80 are often used simultaneously $[39,40]$ to obtain uniform ZIF-8 nanocrystals. Typically, solution \#1 contains 1.5 g surfactants (Span 80 and Tween 80, 9:11 in mass ratio), 0.1 mol 2-methylimidazole (MeIM), and 


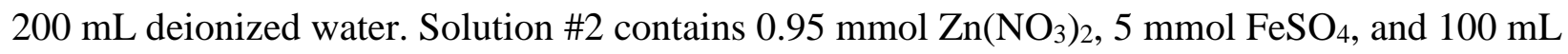
deionized water. Both solutions are stored in round flasks and are bubbled with high purity argon for $1 \mathrm{~h}$. Then solution \#2 is mixed with solution \#1 through a tube connecting the two flasks using compressed Ar to initial the reaction. The mixed solution is stirred at $60^{\circ} \mathrm{C}$ under the protection of Ar for $12 \mathrm{~h}$ until a greyish turbid suspension appears. The resulting product is separated by centrifugation, washed by deaerated ethanol and dried at $80^{\circ} \mathrm{C}$ in vacuum oven for $12 \mathrm{~h}$. The corresponding catalyst was labeled as Fe-Z8-Ar. For a comparison, the Fe-doped ZIF-8 was also prepared under the identical procedures without Ar protection (Fe-Z8-air). As a result, yellowish powder is obtained. The ORR catalysts are prepared by temperature programmed pyrolysis of the Fe-doped ZIF-8 nanocrystals in an Ar atmosphere. Typically, 0.5 g Fe-doped ZIF-8 nanocrystals was heated to $1000{ }^{\circ} \mathrm{C}$ at $5{ }^{\circ} \mathrm{C} \mathrm{min}{ }^{-1}$ under an $\mathrm{Ar}$ stream in a tube furnace, then kept at the peak temperature for $60 \mathrm{~min}$ and then allowed to cool down to room temperature automatically.

\subsection{Materials characterization}

Structure and morphology of studied samples are characterized by X-ray diffraction (XRD, Rigaku $\mathrm{D} / \max 200$ diffractometer, $\mathrm{Cu} \mathrm{K \alpha}$ ), and high-resolution transmission electron microscopy (HRTEM, JEM 2100, $200 \mathrm{kV}$ ). Nitrogen adsorption-desorption isotherms are measured on an Autosorb IQ gas sorption analyzer (Quantachrome) at $77 \mathrm{~K}$. Before testing, samples are degassed at $200{ }^{\circ} \mathrm{C}$ for $2 \mathrm{~h}$. The surface area and pore size distribution are determined by the BrunauerEmmett-Teller (BET) and Quenched Solid Density Functional Theory (QSDFT) methods assuming a slit/cylinder pores model, respectively. The X-ray photoelectron spectroscopy (XPS) analysis is performed on an AXIS-Ultra spectrometer (Kratos Analytical) using monochromatic $\mathrm{Al} \mathrm{K \alpha}$ radiation $(225 \mathrm{~W}, 15 \mathrm{~mA}, 15 \mathrm{kV})$. Content of $\mathrm{C}, \mathrm{H}$ and $\mathrm{N}$ is determined by the combustion method on an elemental analyser (Vario EL). The metal content is obtained by Inductively Coupled 
Plasma-Atomic Emission Spectrometer (ICP-OES), which is performed on a CCD-ICP-OES spectrometer PROFILE SPEC. The samples are first calcinated in air at $900{ }^{\circ} \mathrm{C}$ for $12 \mathrm{~h}$. Then the obtained residue are dissolved in aqua regia to prepare the solution for ICP-OES analysis.

\subsection{Electrochemical measurement}

ORR performance is evaluated in $0.1 \mathrm{M} \mathrm{HClO}_{4}$ solution on a glassy carbon rotating ring disk electrode (RRDE, $5.61 \mathrm{~mm}$ of disk outer diameter, Pine Research Instrumentation, USA). Catalysts are loaded by drop casting isopropanol suspension consisting of catalyst powder and Nafion ionomer. The catalyst loading is controlled at $0.56 \mathrm{mg} / \mathrm{cm}^{2}$. A Pt/XC-72 (20 wt $\%$ ) catalyst with a loading of $20 \mu \mathrm{gPt} \mathrm{cm} \mathrm{cm}^{-2}$ was used as a reference. The reference electrode is a saturated calomel electrode (SCE) and calibrated using reversible hydrogen electrode (RHE). All potentials reported in this work have been converted to the RHE scale. The counter electrode is a graphite rod. The methanol tolerance characterization of the catalysts was carried out in the potential range from 1.2 to $0.0 \mathrm{~V}$ at a scan rate of $50 \mathrm{mV} \mathrm{s}-1$ in $\mathrm{O}_{2}$-saturated $0.1 \mathrm{M} \mathrm{HClO} 4$ containing $1 \mathrm{M}$ methanol. The stability tests of the C-Fe-Z8-Ar catalyst was performed in $\mathrm{O}_{2}$-saturated $0.1 \mathrm{M}$ $\mathrm{HClO}_{4}$ in the potential range from 0.6 to $1.0 \mathrm{~V}$ at room temperature.

In RRDE experiments, the ring potential was set to $1.2 \mathrm{~V}$. Before experiments, the Pt ring was activated by potential cycling in $0.1 \mathrm{M} \mathrm{HClO}_{4}$ from 0 to $1.4 \mathrm{~V}$ at a scan rate of $50 \mathrm{mV} \mathrm{s}^{-1}$ for 10 minutes. ORR steady-state polarization plots were recorded in $\mathrm{O}_{2}$-saturated $0.1 \mathrm{M} \mathrm{HClO}_{4}$ using potential step of $0.03 \mathrm{~V}$ and wait-period of $30 \mathrm{~s}$ between two subsequent potentials, which allow the non-faraday current pass away. This method can prevent the capacitive current from affecting ORR Faraday current. Thus, it doesn't need to subtract capacitive background current. The peroxide yield $\mathrm{H}_{2} \mathrm{O}_{2} \%$ is calculated by the ring current ( $\left.I_{\mathrm{r}}\right)$ and the disk current $\left(I_{\mathrm{d}}\right)$ through following equation [41]: 


$$
\mathrm{H}_{2} \mathrm{O}_{2} \%=\frac{200 I_{r}}{I_{r}+N I_{d}}
$$

Where $\mathrm{N}=0.37$ is the collection efficiency, calibrated by the $\mathrm{K}_{3} \mathrm{Fe}(\mathrm{CN})_{6}$ redox reaction. The kinetic current density $\left(I_{\mathrm{k}}\right)$ used for determining mass activity is calculated by the measured current density $\left(I_{\mathrm{F}}\right)$ and limiting current density $\left(I_{\mathrm{L}}\right)$ as following equations:[41,42]

$$
I_{k}=-\frac{I_{F} I_{L}}{I_{F}-I_{L}}
$$

\section{Results and Discussion}

\subsection{Synthesis of Fe-doped ZIF-8}

A nanocrystal structure of Fe-doped ZIF-8 was shown in Figure 1a. A simple pyrolysis for the Fe-doped ZIF-8 was applied to yield high Fe dispersion on N-doped carbon after Zn elimination. Moreover, the well-defined $\mathrm{FeN}_{4}$ coordinating structure in the Fe-doped ZIF-8 will facilitate the directly formation of the ORR active $\mathrm{FeN}_{\mathrm{x}}$ sites. Su et al. once attempted Fe doping by introducing $\mathrm{Fe}$ (II) during the solvothermal growth of ZIF-8. ${ }^{[43]}$ However, that approach failed to achieve high Fe dispersion in the resulting catalyst with insufficient ORR activity even in alkaline electrolyte. Alternatively, ZIF-8 (or similar Zn based ZIFs) once was physically mixed with N-chelating Fe compounds using ball milling, leading to more efficient $\mathrm{Fe}-\mathrm{N}-\mathrm{C}$ catalysts after pyrolysis as demonstrated by Liu et al [35,36] and Dodelet et al [16]. Therefore, profound insights into the synthetic process particularly for the interactions between Fe and ZIF-8 framework are certainly needed. In our synthesis, we discovered that an $\mathrm{O}_{2}$-free environment is desirable to realize optimal Fe doping directly into ZIF-, which are crucial for achieving uniform Fe dispersion at atomic level with high ORR activity. 
In our newly developed synthesis, Fe-doped ZIF-8 was prepared in an aqueous emulsion containing metal salts $\left(\mathrm{FeSO}_{4} \cdot 7 \mathrm{H}_{2} \mathrm{O}\right.$ and $\mathrm{Zn}\left(\mathrm{NO}_{3}\right) \cdot 6 \mathrm{H}_{2} \mathrm{O}$ in a molar ratio of 5:95), 2methylimidazole and surfactants (Span 80 and Tween 80 ) at $60^{\circ} \mathrm{C}$. After stirring for $24 \mathrm{~h}$, the solid product is collected by centrifugation followed by washing with ethanol. The preparation is carried out in both ambient air and an Ar atmosphere. The obtained products are denoted as Fe-Z8-air and Fe-Z8-Ar, appearing yellowish and light grey colors, respectively (Figure S1). These inexpensive surfactants are able to reduce the ZIF-8 particle size with homogeneous distribution in solution. As shown in the transmission electron microscopy (TEM) images, Fe-Z8-Ar is composed of nanoparticles about $40 \mathrm{~nm}$ in diameter (Figure 1b), similar to that of ZIF-8 prepared under the identical conditions but without Fe doping (Figure S2). However, inhomogeneity features are found in Fe-Z8-air, suggested by a broader distribution of particle sizes in TEM images (Figure 1c). X-ray diffraction (XRD) patterns indicate that these two Fe-doped ZIF-8 samples have similar crystal structure to the undoped ZIF-8 (Figure 1d), suggesting Fe doping at such a low level (5 mol\%) does not affect the ZIF-8 structure. 

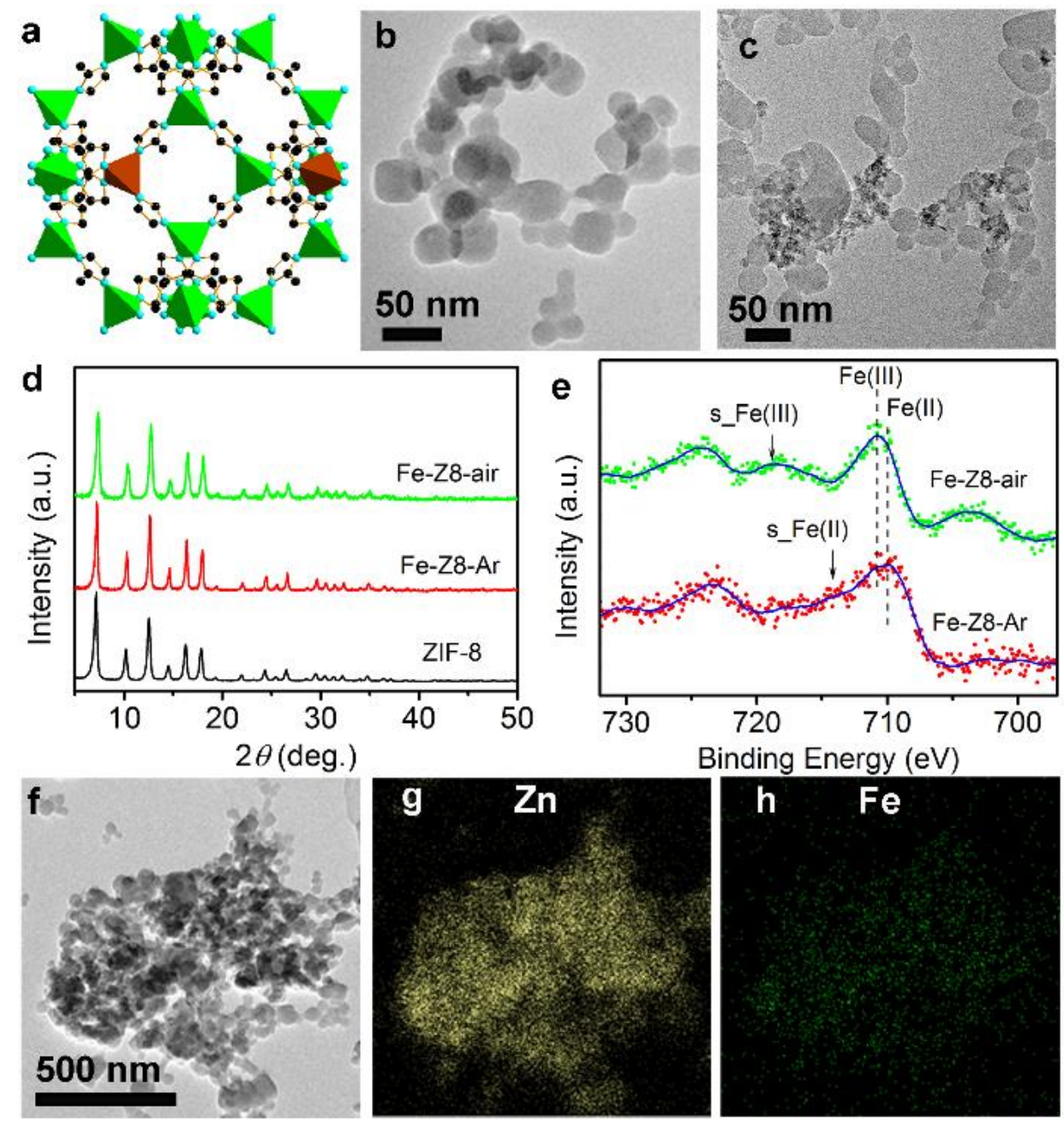

Figure 1. (a) Schematic illustration of the structure of Fe doped ZIF-8. ZnN4 and FeN4 tetrahedrons are shown in green and yellow, respectively. (b-c) TEM images of Fe-Z8-Ar (b) and Fe-Z8-air (c). (d-e) XRD patterns (d) and XPS spectra (e) of Fe-Z8-Ar and Fe-Z8-air. The XRD pattern of ZIF-8 is also shown for comparison in (d). The satellite peak in XPS spectra (e) are denoted by the arrows. (f-h) Elemental mapping of Fe-Z8-Ar in the scanning TEM mode of the corresponding region in (f).

The Fe oxidation states in the two Fe-doped ZIF-8 samples are studied by X-ray photoelectron spectroscopy (XPS, Figure 1e). Fe-Z8-Ar shows a main peak at $709.9 \mathrm{eV}$ and a satellite peak $\sim 15$ eV, corresponding to exclusive divalent Fe. However, the main peak of Fe-Z8-air shifts to 710.9 
$\mathrm{eV}$ accompanied by a more notable shift of the satellite peak to $718 \mathrm{eV}$. These features are indicative of trivalent $\mathrm{Fe}$, which are very similar to that of $\mathrm{Fe}$ (III) oxide/hydroxide reported in previous studies $[44,45]$. In addition, the small hump observed at $705 \mathrm{eV}$ for the Fe-Z8-air sample is related to $\mathrm{Fe} 2 \mathrm{p} 3 / 2$ due to trace of the metallic aggregates. The comparison suggests that ambient air is able to oxidize Fe (II) into Fe (III) during the preparation process for Fe-doped ZIF-8.

In principle, $\mathrm{Fe}^{2+}$ can form four fold coordinated tetrahedral complexes with imidazole-type ligands $[46,47]$. The similar local coordination environment and isovalent nature make $\mathrm{Fe}^{2+}$ substitution for $\mathrm{Zn}^{2+}$ in ZIF-8 favorable. Homogenous Fe distribution in Fe-Z8-Ar is further confirmed by elemental mapping (Figure 1f-h). Such Fe substitution effect was also observed by Tian et al. using Mössbauer spectroscopy to study ZIF-8 that is in contact with Fe (II) complexes during an ion exchange process in aqueous solution [48].

\subsection{Synthesis of Fe-N-C catalysts derived from Fe-doped ZIF-8}

Subsequently, the Fe-N-C catalysts are prepared by a heat treatment of the ZIF nanoparticles at $1000^{\circ} \mathrm{C}$ in Ar atmosphere. Catalysts derived from undoped ZIF-8, Fe-Z8-Ar and Fe-Z8-air are denoted as C-Z8, C-Fe-Z8-Ar, and C-Fe-Z8-air, respectively. Remarkable structural similarity is found for C-Z8 and C-Fe-Z8-Ar. In the XRD patterns (Figure 2a), both samples only show two broad peaks centered at $25^{\circ}$ and $43^{\circ}$ corresponding to partially graphitized carbon. XPS analysis (Figure 2b) further indicates divalent Fe is exclusively found in C-Fe-Z8-Ar with a single peak at $\sim 710 \mathrm{eV}$. The divalent nature suggests strong interaction between the highly dispersed Fe and the $\mathrm{N}$-doped carbon $[49,50]$. This results agrees with the porous carbon morphology observed in the TEM images (Figure 2c and 2d). Furthermore, elemental qualification determined by both Vario EL Elemental analyzer (Table S1) and XPS (Table S2) indicated that, different from C-Z8 which is virtually $\mathrm{N}$ doped carbon, C-Fe-Z8-Ar does contain $3.35 \mathrm{wt} \% \mathrm{Fe}$ (Table S1). Thus, despite of 
the absence of observable Fe agglomerates, $\mathrm{Fe}$ is detected in the C-Fe-Z8-Ar sample by elemental mapping, showing uniform distribution of $\mathrm{Fe}$ on $\mathrm{N}$-doped porous carbon (Figure 2f-h). In MOF precursor, Fe-Z8-Ar, Fe is coordinated by four $\mathrm{N}$ atoms from 2-methylimidazole (Figure 1a), which is favorable for the formation of the uniform $\mathrm{FeN}_{\mathrm{x}}$ sites into the porous carbon matrix after a simple thermal conversion $[10,35]$. It should be noted that the residual $\mathrm{Zn}$ is indeed negligible below 0.05 at\% for Fe-based catalysts. The XPS survey spectra of C-Z8, C-Fe-Z8-Ar, and C-FeZ8-air also were compared in Figure S3. It should be not an issue to impair the long term stability in fuel cells due to the contamination of ionomer and membrane. Therefore, the additional acid leaching treatment may not be required for such-synthesized catalysts.
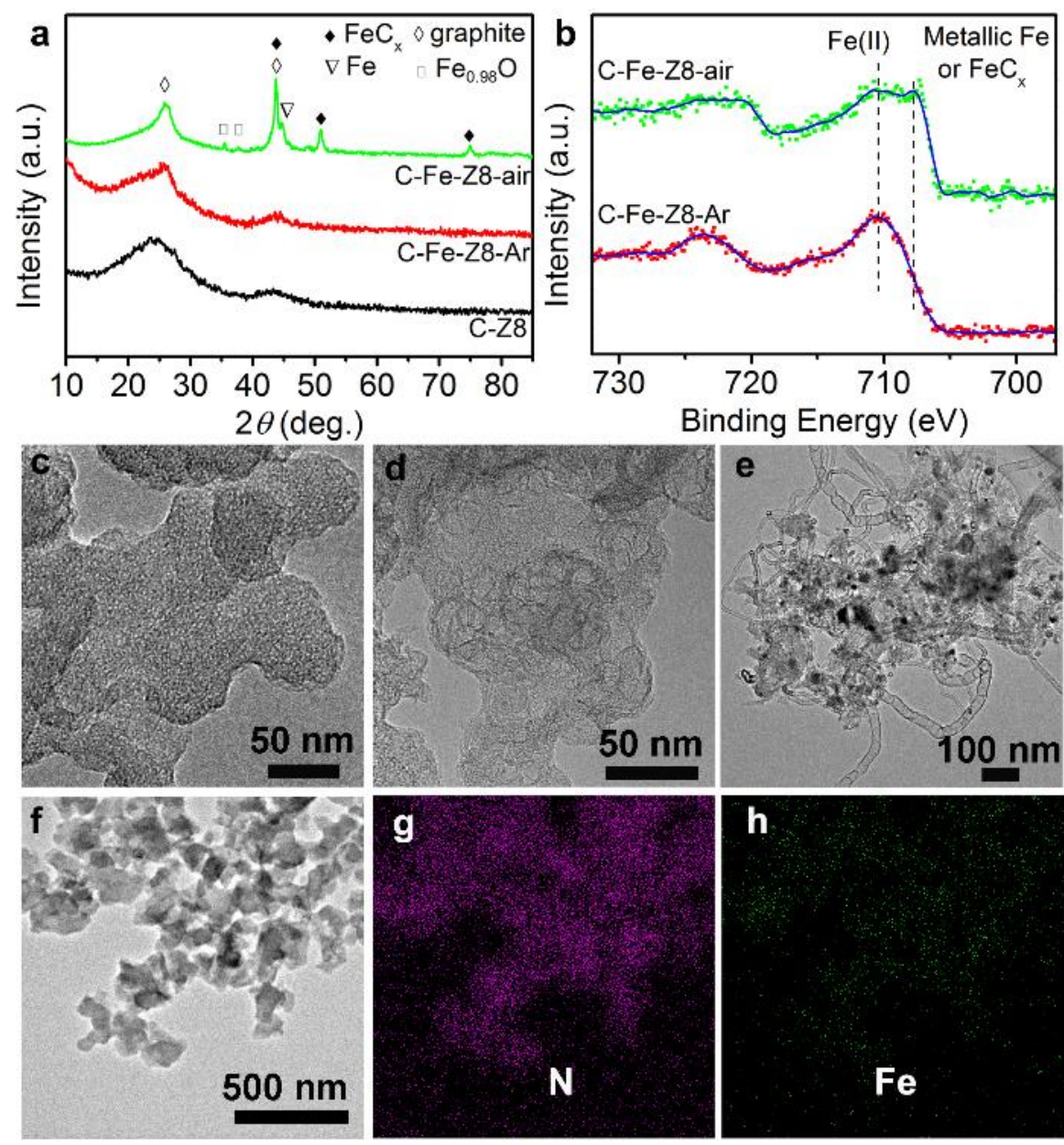
Figure 2. (a) XRD patterns of C-Z8, C-Fe-Z8-Ar and C-Fe-Z8-air. (b) High resolution Fe 2p XPS spectra of C-Fe-Z8-Ar and C-Fe-Z8-air. (c-e) TEM images of C-Z8 (c), C-Fe-Z8-Ar (d) and C-Fe-Z8-air (e). (f-h) Elemental mapping of C-Fe-Z8-Ar in the scanning TEM mode of the corresponding region in (f).

Similar to C-Fe-Z8-Ar, the C-Fe-Z8-air contains 4 wt\% Fe, which was prepared from the Fedoped ZIF without Ar protection. Considerable amount of metallic Fe, iron carbide and trace Fe(II) oxide were clearly detected by the associated peaks in XRD patterns. The XPS peak at $707 \mathrm{eV}$ in Figure $2 \mathrm{~b}$ is also indicative of metallic Fe in the $\mathrm{C}$-Fe-Z8-air sample. These are in agreement with the crystalline Fe containing particles detected by TEM (Figure 2e). A morphology comparison determined by SEM images between C-Fe-Z8-Ar and the C-Fe-Z8-air presents in Figure 3.
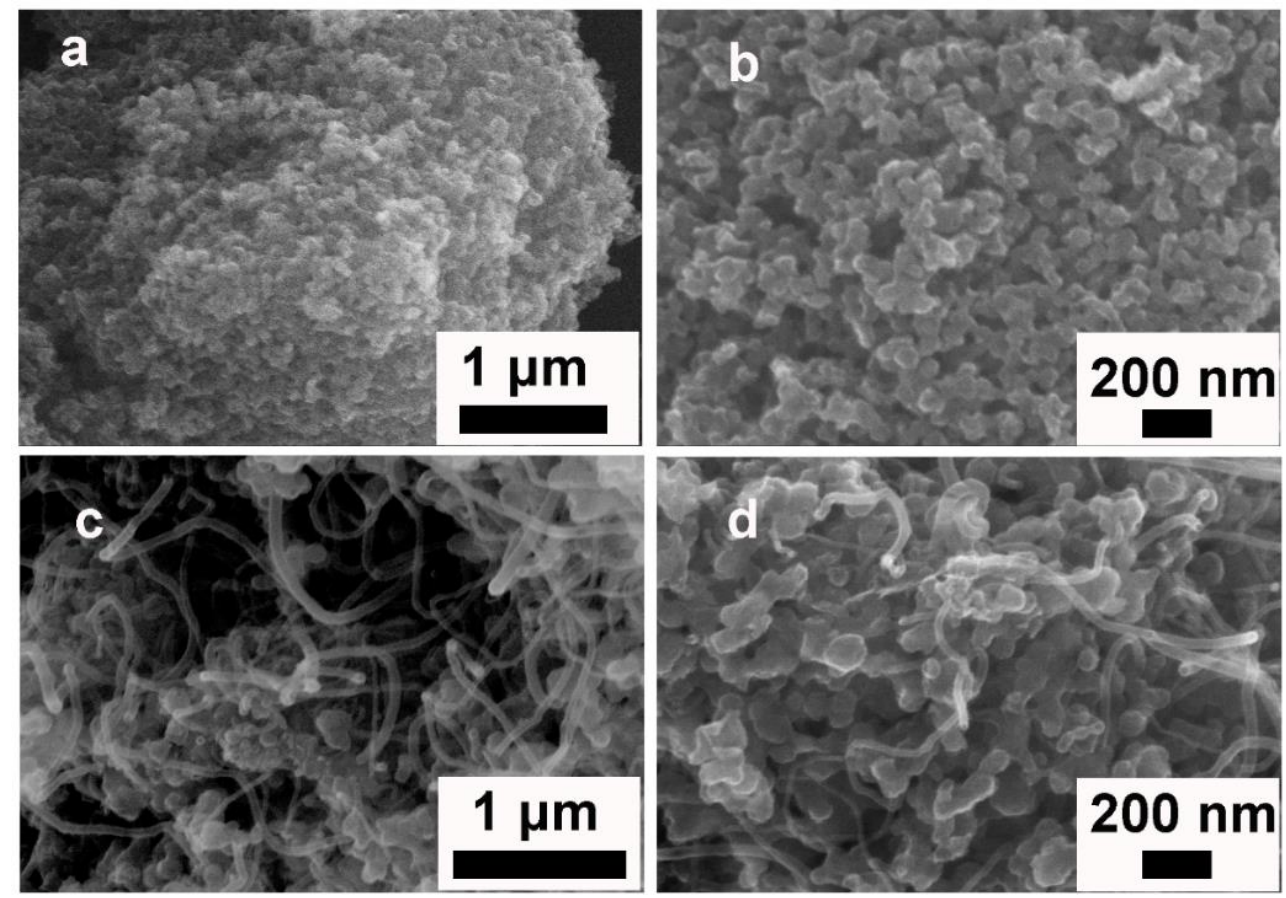

Figure 3. SEM images of C-Fe-Z8-Ar (a, b) and C-Fe-Z8-air (c,d).

Unlike amorphous or partially graphitized structure observed with the C-Fe-Z8-Ar, there appear dominant carbon nanotube-like structures in C-Fe-Z8-air. The formation of carbon 
nanotubes is likely catalyzed by the generated metallic $\mathrm{Fe}$ or $\mathrm{FeC}_{\mathrm{x}}$ in catalysts. Usually, the formation of highly graphitized nanocarbon such as carbon tube, onion-like carbon, and graphenesheet structures were extensively observed in high-performance Fe-N-C catalysts [24,51-53]. Initially, we thought that these highly graphitized nanocarbons in catalysts dictate active site generation and was directly linked to the enhanced ORR activity and stability. Oppositely, in this work, dominant amorphous or partially graphitized carbon with uniform distributions of $\mathrm{N}$ and $\mathrm{Fe}$ were found in the C-Fe-Z8-Ar catalyst showing even higher ORR activity ( $E_{1 / 2}$ up to $0.82 \mathrm{~V}$ vs. RHE, to be discussed later) and stability relative to graphitized nanocarbon-rich Fe-N-C catalysts $(0.80 \mathrm{~V})$. Thus, it seems that the highly graphitized carbon structures in the $\mathrm{Fe}-\mathrm{N}-\mathrm{C}$ catalysts are not necessary for generating high ORR activity. At least, it should be noted that dominant agglomerated iron compounds in catalysts suggest a non-uniform dispersion of active iron sites, which is controversial to our intention to increase density of active sites. Interestingly, formation of carbon nanotubes was also observed in the pyrolysis product of Fe-doped ZIF-8 by Su et al. showing insufficient ORR activity [43]. The Fe-doped ZIF-8 in their work was obtained from a solvothermal reaction but without deliberately eliminating the ambient air, very similar to the FeZ8-air in this work. As shown in Figure 4a, the Brunauer-Emmett-Teller (BET) surface area of C-Fe-Z8 air is also much lower $\left(610 \mathrm{~m}^{2} / \mathrm{g}\right)$ compared to those of C-Fe-Z8-Ar $\left(969 \mathrm{~m}^{2} / \mathrm{g}\right)$ and Fefree C-Z8 (1049 m²/g). As for Fe-N-C catalysts, larger surface areas, higher ORR activity [54]. Therefore, controlling catalyst morphology with improved surface areas is also critical for enhancing catalytic performance. It should be noted that the C-Fe-Z8-Ar processes dominant microporous structure compared to C-Fe-Z8-air (Figure 4b), which is favorable for mass transport during the ORR $[23,55]$. 

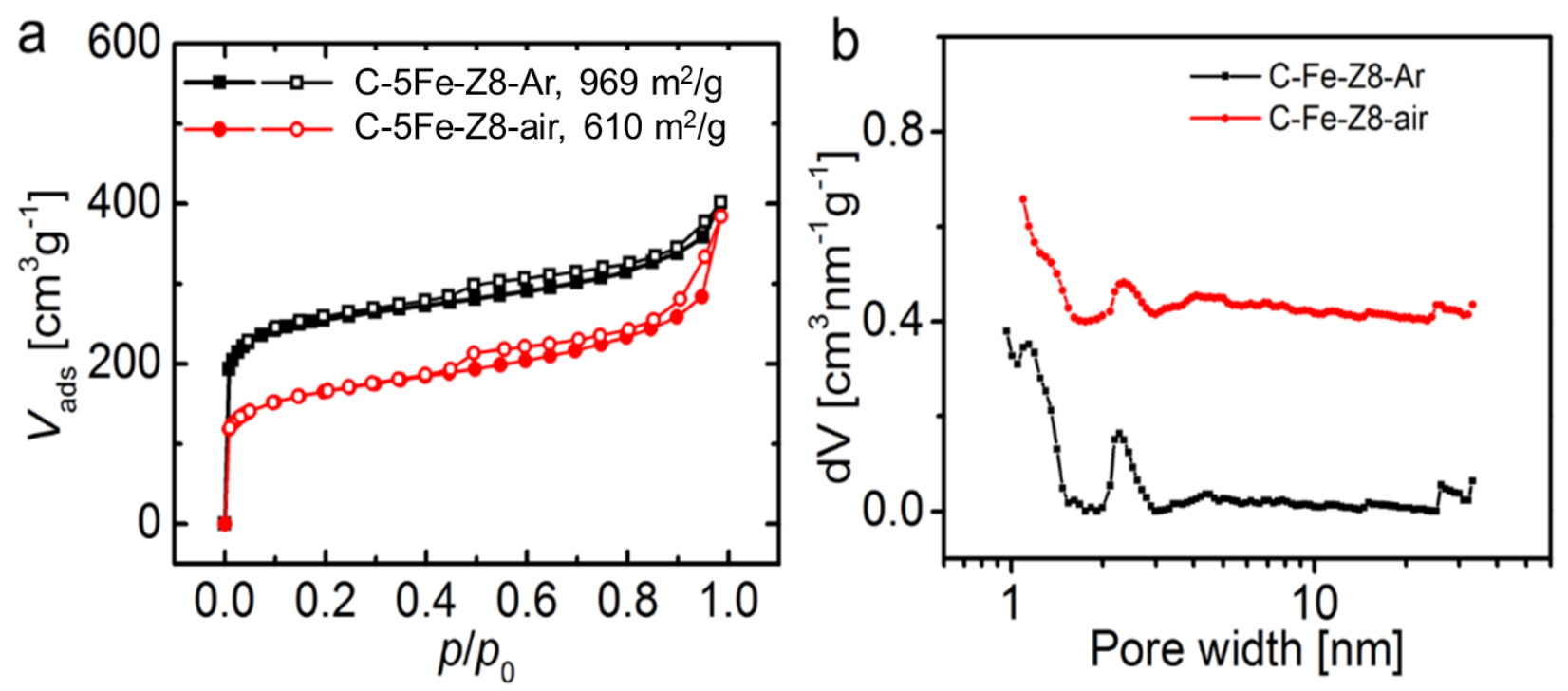

Figure 4. Nitrogen adsorption-desorption isotherms (a) and pore size distribution (b) for C-Fe-Z8-Ar and C-Fe-Z8-air catalysts.

The nature of the nitrogen dopant was believed to be crucial for the ORR activity of Fe-N-C type catalysts. The N 1s XPS spectra (Figure 5) suggest that both C-Fe-Z8-Ar and C-Fe-Z8-air contain dominant graphitic $(401.8 \mathrm{eV})$ and pyridinic $(398.7 \mathrm{eV}) \mathrm{N}$ along with small fraction of oxidized nitrogen (403-405 eV). The pyridinic $\mathrm{N}$ also includes contribution from the $\mathrm{N}$ bonded to metal which should appear at $\sim 399.2 \mathrm{eV}$ and largely overlaps with the pyridinic $\mathrm{N}$ in the measured spectra. Importantly, the C-Fe-Z8-Ar sample contains higher fraction of pyridinic N compared to the C-Fe-Z8-air. In addition, the total nitrogen content of C-Fe-Z8-Ar $(6.9 \mathrm{wt} \%)$ is more than twice of C-Fe-Z8-air (2.8 wt\%, Table S1). Considering the much higher Fe dispersion with exclusively divalent state, the higher amount of pyridinic $\mathrm{N}$ in the $\mathrm{C}-\mathrm{Fe}-\mathrm{Z} 8-\mathrm{Ar}$ is also a strong indication of more Fe-N bonding in this sample. 


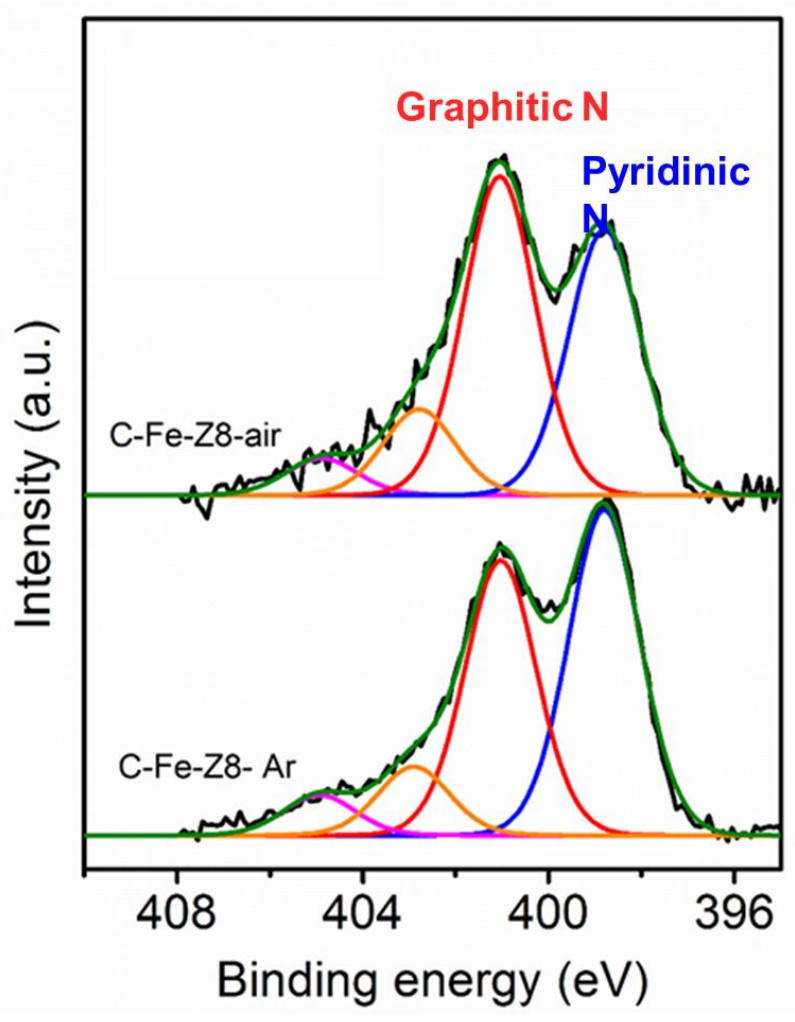

Figure 5. High resolution N 1s XPS spectra of C-Fe-Z8-Ar and C-Fe-Z8-air.

\subsection{Electrochemical activity and stability}

Figure 6a shows the ORR polarization plots and $\mathrm{H}_{2} \mathrm{O}_{2}$ yield for the four catalysts measured on a RRDE. Onset potential is defined as the potential that is able to generate a current density of 0.1 $\mathrm{mA} / \mathrm{cm}^{2}$ during the ORR based on the recorded steady state polarization plots. For the best performing C-Fe-Z8-Ar, the onset potential $\left(E_{\mathrm{on}}\right)$ and half-wave potential $\left(E_{1 / 2}\right)$ are determined to be 0.95 and $0.82 \mathrm{~V}$, respectively. Compared to the commercial Pt/XC-72 (20 wt\% Pt) catalyst, the newly developed C-Fe-Z8-Ar only shows slightly negative $E_{1 / 2}$ value by $\sim 40 \mathrm{mV}$ in more challenging acidic electrolyte and significantly reduce the current gap between NPMC and Pt/C [56]. In addition, these values are much higher than those of C-Fe-Z8-air (0.84 and $0.65 \mathrm{~V}$ for Eon and $\left.E_{1 / 2}\right)$ without well-dispersed atomic iron distribution. Furthermore, the calculated mass activity 
of C-Fe-Z8-Ar is higher than that of C-Fe-Z8-air (Figure S4). In addition, Tafel slopes for various samples were determined in relatively high potential ranges. The value for $\mathrm{Pt} / \mathrm{C}$ is $-60 \mathrm{mV} / \mathrm{dec}$. Both C-Fe-Z8-Ar and C-Fe-Z8-air have similar slopes of -70 and $-77 \mathrm{mV} / \mathrm{dec}$. As for the iron-free $\mathrm{C}-\mathrm{Z8}$, the value of slope is determined to be $-236 \mathrm{mV} /$ decade, indicating, instead of first electron transfer $(-118 \mathrm{mV} / \mathrm{dec})$ and possible immigration of intermediates $(-59 \mathrm{mV} / \mathrm{dec}), \mathrm{O}_{2}$ adsorption become a new rate determined step [57]. Thus, C-Fe-Z8-Ar is much more active than C-Fe-Z8air. As expected, both Fe containing samples exhibit higher ORR activity than the Fe-free C-Z8 sample, which agrees with the general accepted conclusion that Fe is indispensable for good ORR activity in acidic media $[32,58]$. Noteworthy, due to the very porous structures for the catalyst, the measured limiting current densities are often higher than those calculated theoretical value by using flat disk electrode. This is very common for good catalysts to generate increased limiting current due to high-surface areas and increased active sites in 3D electrodes. 

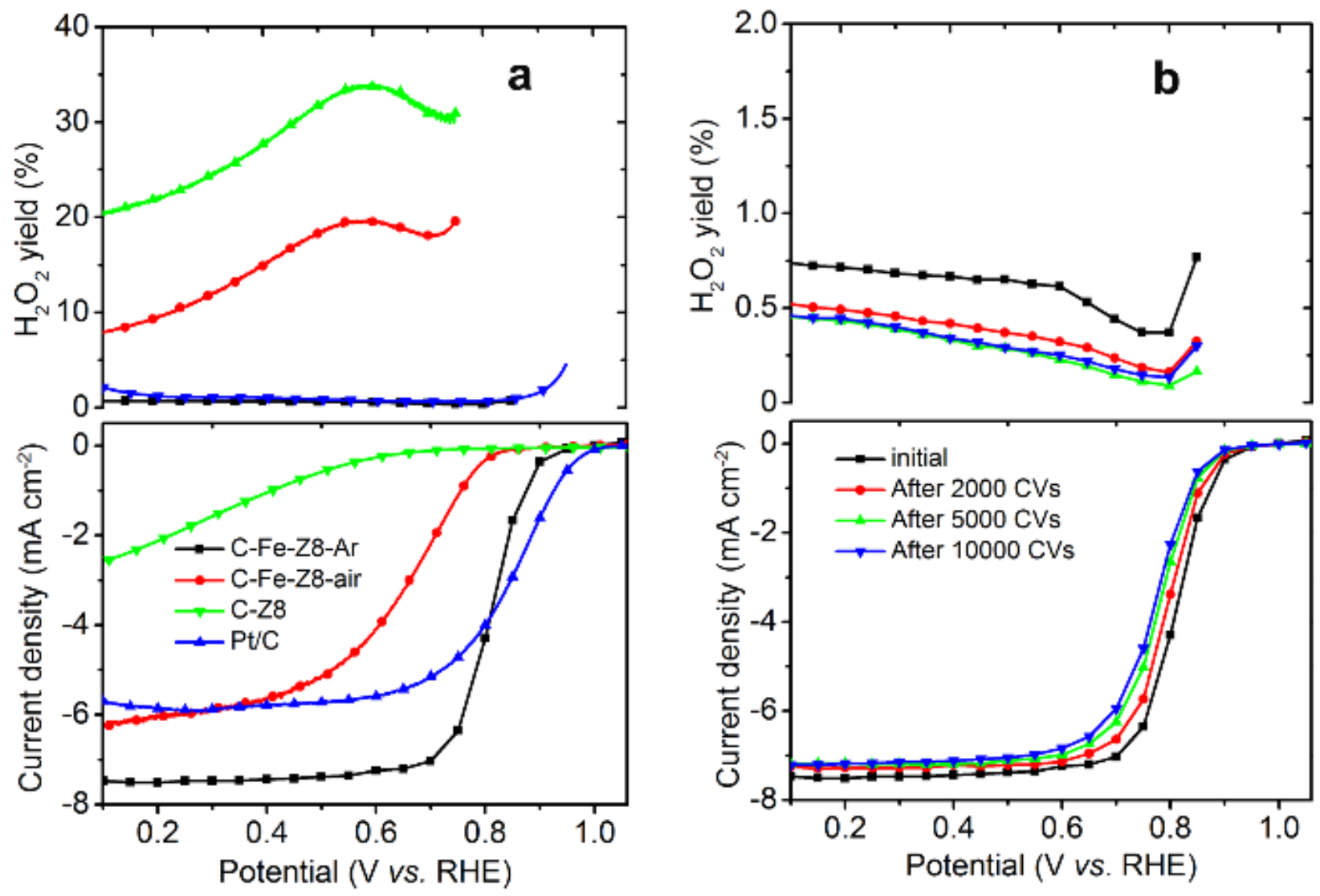

Figure 6. (a) Steady-state polarization curves (bottom) and $\mathrm{H}_{2} \mathrm{O}_{2}$ yield (top) of the ORR catalysts derived from ZIF-8, Fe-doped ZIF-8 and E-TEK Pt/XC-72 with 20 wt\% Pt loading. (b) Steady-state polarization curves (bottom) and $\mathrm{H}_{2} \mathrm{O}_{2}$ yield (top) of $\mathrm{C}-\mathrm{Fe}-\mathrm{Z} 8$-Ar after different cyclic voltammetry cycles. All tests are carried out on a rotating ring disk electrode (RRDE) rotating at $1600 \mathrm{rpm}$ in $\mathrm{O}_{2}$-saturated $0.1 \mathrm{M} \mathrm{HClO}_{4}$. The non-precious metal catalysts loading is controlled at $0.56 \mathrm{mg} / \mathrm{cm}^{2}$. The Pt/C loading is controlled at 20 $\mu \mathrm{gPt} / \mathrm{cm}^{2}$.

Regarding the insignificant loading dependence of ORR activity as shown in Figure S5a, it is due to the C-Fe-Z8-Ar catalyst is highly active and contain high-density active sites in the 3D porous electrode, capable of providing sufficient active sites even at a low loading. Four-electron selectivity is another criterion for ORR catalysts. An ideal ORR catalyst for PEFCs should catalyze 
$\mathrm{O}_{2}$ to $\mathrm{H}_{2} \mathrm{O}$ via a 4e- reduction pathway without $\mathrm{H}_{2} \mathrm{O}_{2}$ formation. Calculated from RRDE data using Equation 1, the electron transfer number is 3.98 for the C-Fe-Z8-Ar in the whole potential region from 0.2 to $0.8 \mathrm{~V}$, indicating extremely low $\mathrm{H}_{2} \mathrm{O}_{2}$ yield below $1 \%$. Importantly, there is no monotonic variation trend of $\mathrm{H}_{2} \mathrm{O}_{2}$ yield with catalyst loadings (Figure S5b), indicating a real direct 4electron reduction, rather than a stepwise $2 \mathrm{e}^{-}+2 \mathrm{e}^{-}$reduction mechanism [59-61]. Thus, a more noticeable advantage of the catalyst is the extremely low $\mathrm{H}_{2} \mathrm{O}_{2}$ yield $(<1 \%)$ without loading dependence. $\mathrm{H}_{2} \mathrm{O}_{2}$ is undesirable for Fe-based ORR catalyst due to the possible Fenton reaction in the presence of $\mathrm{Fe}^{2+}$, which will damage the Nafion ${ }^{\circledR}$ membrane in PEFCs [62]. For the C-Fe-Z8-air, the electron transfer number is between 3.35 and 3.81 in the same potential region. The corresponding $\mathrm{H}_{2} \mathrm{O}_{2}$ yield is as high as $20 \%$.

In this work, the optimal Fe content is determined around 5wt\% in Fe-doped ZIF-8. We also prepared catalysts with nominal Fe content up to $10 \mathrm{wt} \%$ and down to $1 \mathrm{wt} \%$. But the yielded ORR activities are inferior to the catalyst with optimal 5wt\% Fe (Figure S6). Meanwhile, we found significant Fe-containing aggregates in the TEM image of C-10Fe-Z8-Ar (Figure S7a), which was further verified as $\mathrm{Fe}$ and $\mathrm{Fe}_{3} \mathrm{C}$ by analyzing its $\mathrm{XRD}$ pattern (Figure S7b). This is in agreement with the main conclusion of the paper, which high Fe dispersion is crucial to achieve good ORR performance. Furthermore, the best performing C-Fe-Z8-Ar catalyst also shows very high methanol tolerance and sufficient stability. As shown in Figure S8, introducing methanol has little impact on the ORR peak of the C-Fe-Z8-Ar catalyst. The long term stability is assessed by the ORR polarization curves before and after different cycles in the range of 0.6-1.0 V. Figure 6b indicated that its $E_{1 / 2}$ is only negatively shifted by $40 \mathrm{mV}$ after 10,000 cycles. The slight degradation may be attributed to loss of active iron sites hosted in the carbon matrix caused by carbon oxidation [63]. Interestingly, the $\mathrm{H}_{2} \mathrm{O}_{2}$ yield is further reduced to less than $0.5 \%$ during the potential cycling test. 
Therefore, compared to the state-of-the-art Fe-N-C catalysts, the newly developed C-Fe-Z8-Ar from MOFs demonstrates a very high half-wave potential and significantly reduced $\mathrm{H}_{2} \mathrm{O}_{2}$ yield lower than $1 \%[3,12,50,64]$. A comprehensive comparison data with other Fe-N-C catalysts are summarized in Table S2.

\subsection{Role of $\mathrm{Fe}(\mathrm{II})$ in enhancing activity}

The enhanced ORR activity of the C-Fe-Z8-Ar catalyst is mainly due to the increased density of active sites associated with high $\mathrm{Fe}$ dispersion at atomic level. Particularly, the C-Fe-Z8-Ar catalyst contains homogeneously distributed Fe without observable Fe-containing particles, capable of maximizing the ORR active Fe sites. The highly porous morphology also allows facile access to the Fe sites by $\mathrm{O}_{2}$. The structure of Fe-doped ZIF-8 illustrated in Figure 1a is ideal to achieve uniform $\mathrm{Fe}$ distribution in the catalyst during the thermal conversion. In this structure, $\mathrm{Fe}$ is homogeneously dispersed by $\mathrm{Zn}$, in which the $\mathrm{Zn}$ species itself is removable during the thermal conversion. Thus, aggregation of $\mathrm{Fe}$, which frequently occurs at high temperature treatment, is effectively minimized through using Fe-doped ZIF-8 MOF precursors.

It should be noted that, to achieve homogeneous Fe doping in ZIF-8, $\mathrm{Fe}^{2+}$ is preferred compared to $\mathrm{Fe}^{3+}$, because $\mathrm{Fe}^{2+}$ and $\mathrm{Zn}^{2+}$ are isovalent with similar ion radius (Cation radii: $\mathrm{Fe}^{2+}$ $62 \mathrm{pm}$ and $\mathrm{Zn}^{2+} 60 \mathrm{pm}$ ) [65] and stabilization constants with 2-methylimidazole [48]. As a result, tetrahedral $\mathrm{FeN}_{4}$ structure has been extensively found in complexes composed of $\mathrm{Fe}^{2+}$ and imidazole type ligands $[46,47,66]$. However, Fe doping in ZIF-8 is carried out in a weakly alkaline environment ( $\mathrm{pH} \sim 10$ ), in which $\mathrm{Fe}(\mathrm{II})$ can be easily oxidized to $\mathrm{Fe}(\mathrm{III})$ by ambient $\mathrm{O}_{2}$. $\mathrm{Fe}^{3+}$ has much smaller radius (49-55 pm) and typically adopts six fold coordination structure in imidazole complexes [66]. Thus, $\mathrm{Fe}^{3+}$ substitution for $\mathrm{Zn}^{2+}$ in $\mathrm{ZIF}-8$ will cause significant structural distortion, which is less favorable. Furthermore, $\mathrm{Fe}^{3+}$ shows much higher hydrolysis tendency 
compared to the divalent cations $\left(K_{\mathrm{sp}}: 10^{-38.5}\right.$ for $\mathrm{Fe}(\mathrm{OH})_{3}, 10^{-16.5}$ for $\mathrm{Zn}(\mathrm{OH})_{2}$ and $10^{-16.3}$ for $\left.\mathrm{Fe}(\mathrm{OH})_{2}\right)$ [65]. Thus, in a weakly alkaline solution, hydrolysis of $\mathrm{Fe}^{3+}$ is highly favorable, as clearly evidenced by the detection of Fe(III) oxide/hydroxide in XPS (Figure 1e). The inhomogeneity observed in the TEM image (Figure 1c) is also very likely due to the hydrolysis of $\mathrm{Fe}^{3+}$.

Therefore, an $\mathrm{O}_{2}$-free environment is required for stabilizing $\mathrm{Fe}^{2+}$ to facilitate homogeneous Fe substitution for $\mathrm{Zn}$ in ZIF-8, which is crucial for uniform Fe distribution in the catalyst. Otherwise, oxidation of $\mathrm{Fe}^{2+}$ to $\mathrm{Fe}^{3+}$ and the following hydrolysis of $\mathrm{Fe}^{3+}$ will result in $\mathrm{Fe}$ aggregation in the derived Fe-N-C catalyst. This key factor has been overlooked in previous study using the similar synthetic strategy, which yielded a Fe-N-C catalyst with moderate ORR performance similar to C-Fe-Z8-air in this work [33]. The negative impact of $\mathrm{O}_{2}$, however, is less critical in Fe/ZIF-8 composites prepared by ball milling when stable N-chelated Fe complexes are used. In this case, the driving force to disperse Fe in ZIF-8 is physical mixing rather than chemical Fe substitution for $\mathrm{Zn}[16,35,36]$.

\section{Conclusions}

In summary, starting with homogeneously Fe-doped ZIF-8, a highly active and stable Fe-N-C catalyst with highly dispersed Fe sites is obtained via facile one-step thermal conversion without requirements of post-leaching and heating treatments. The simple synthesis procedure is low-cost and allow for catalyst production in large scale. A significant innovation during the synthesis is that, for the first time, Fe was successfully doped into ZIF-8 by partially replacing $\mathrm{Zn}$ ions, when maintaining divalent during the synthesis process. During the thermal treatments, nitrogen and iron coordination $\left(\mathrm{FeN}_{4}\right)$ containing ZIF-8 framework directly converts into N-doped carbon with uniform Fe distribution without any agglomerated iron particles. The zinc species is eliminated 
due to its high volatility, yielding a highly porous carbon morphology. Notably, the control of an $\mathrm{O}_{2}$-free environment for stabilizing $\mathrm{Fe}(\mathrm{II})$, rather than forming $\mathrm{Fe}(\mathrm{III})$, during the preparation of Fe-doped ZIF-8 precursor was found to be extremely crucial for generating uniform Fe distribution at atomic level. This strategy effectively prevents formation of inactive iron aggregates.

Importantly, the new Fe-N-C catalyst exhibits very high ORR activity in terms of its half-wave potential (as high as $0.82 \mathrm{~V}$ vs. RHE) and extremely low $\mathrm{H}_{2} \mathrm{O}_{2}$ yield $(<1 \%)$ as well as sufficient potential cycling stability in the more challenging acidic electrolyte. This effort significantly reduces the activity gap between current NMPCs and Pt/C catalysts in more challenging acidic media. The remarkably enhanced activity is primarily due to the homogeneous Fe distribution at an atomic level which significantly increases the density of the ORR active Fe sites. An oxygen free environment is necessary to obtain homogeneously Fe dope ZIF-8, the critical precursor for the high performance Fe-N-C ORR catalyst with high Fe dispersion. An important finding from this work is that highly graphitized nanocarbons once extensively observed in NPMCs are not necessities for high ORR activity, which differs to our previous observation toward the ORR electrocatalysis.

\section{ACKNOWLEDGMENT}

The authors acknowledge financial support from National Natural Science Foundation of China (No. U1201241, 11375020, 51431001 and 21321001). X. J. Wang acknowledges the Ph.D.

Exchange Program of Peking University. G.Wu acknowledges the Star-up funding from the University at Buffalo (SUNY) along with NSF (CBET-1511528) and U.S. Department of Energy, Fuel Cell Technologies Office (FCTO) Incubator Program (DE-EE000696). 


\section{References}

[1] M. Lefevre, E. Proietti, F. Jaouen, J.-P. Dodelet, Science, 324 (2009) 71-74.

[2] Z. Chen, D. Higgins, A. Yu, L. Zhang, J. Zhang, Energy \& Environmental Science, 4 (2011) 3167-3192.

[3] G. Wu, K.L. More, C.M. Johnston, P. Zelenay, Science, 332 (2011) 443-447.

[4] W. Xia, A. Mahmood, Z. Liang, R. Zou, S. Guo, Angewandte Chemie International Edition, (2015).

[5] F. Jaouen, E. Proietti, M. Lefevre, R. Chenitz, J.-P. Dodelet, G. Wu, H.T. Chung, C.M. Johnston, P. Zelenay, Energy \& Environmental Science, 4 (2011) 114-130.

[6] F. Jaouen, J. Herranz, M. Lefevre, J.-P. Dodelet, U.I. Kramm, I. Herrmann, P. Bogdanoff, J. Maruyama, T. Nagaoka, A. Garsuch, J.R. Dahn, T. Olson, S. Pylypenko, P. Atanassov, E.A. Ustinov, ACS Applied Materials \& Interfaces, 1 (2009) 1623-1639.

[7] J.S. Lee, G.S. Park, S.T. Kim, M. Liu, J. Cho, Angewandte Chemie, 125 (2013) 1060-1064.

[8] A. Serov, K. Artyushkova, E. Niangar, C. Wang, N. Dale, F. Jaouen, M.-T. Sougrati, Q. Jia, S. Mukerjee, P. Atanassov, Nano Energy, 16 (2015) 293-300.

[9] J. Zhang, L. Dai, ACS Catalysis, 5 (2015) 7244-7253.

[10] Y. Jiao, Y. Zheng, M. Jaroniec, S.Z. Qiao, Chemical Society Reviews, 44 (2015) 20602086.

[11] R. Jasinski, Nature, 201 (1964) 1212-1213.

[12] H. Zhong, C. Deng, Y. Qiu, L. Yao, H. Zhang, Journal of Materials Chemistry A, 2 (2014) 17047-17057.

[13] Y. Shao, J. Liu, Y. Wang, Y. Lin, Journal of Materials Chemistry, 19 (2009) 46-59. 
[14] V. Nallathambi, J.-W. Lee, S.P. Kumaraguru, G. Wu, B.N. Popov, Journal of Power Sources, 183 (2008) 34-42.

[15] B. Wang, Journal of Power Sources, 152 (2005) 1-15.

[16] E. Proietti, F. Jaouen, M. Lefevre, N. Larouche, J. Tian, J. Herranz, J.-P. Dodelet, Nature Communications, 2 (2011) 416.

[17] G. Wu, C.M. Johnston, N.H. Mack, K. Artyushkova, M. Ferrandon, M. Nelson, J.S. Lezama-Pacheco, S.D. Conradson, K.L. More, D.J. Myers, Journal of Materials Chemistry, 21 (2011) 11392-11405.

[18] G. Wu, N.H. Mack, W. Gao, S. Ma, R. Zhong, J. Han, J.K. Baldwin, P. Zelenay, ACS Nano, 6 (2012) 9764-9776.

[19] G. Wu, Z. Chen, K. Artyushkova, F.H. Garzon, P. Zelenay, ECS Transactions, 16 (2008) 159-170.

[20] M. Ferrandon, A.J. Kropf, D.J. Myers, K. Artyushkova, U. Kramm, P. Bogdanoff, G. Wu, C.M. Johnston, P. Zelenay, Journal of Physical Chemistry C, 116 (2012) 16001-16013.

[21] U.I. Kramm, J. Herranz, N. Larouche, T.M. Arruda, M. Lefèvre, F. Jaouen, P. Bogdanoff, S. Fiechter, I. Abs-Wurmbach, S. Mukerjee, J.-P. Dodelet, Physical Chemistry Chemical Physics, 14 (2012) 11673.

[22] U.I. Kramm, M. Lefevre, N. Larouche, D. Schmeisser, J.-P. Dodelet, Journal of the American Chemical Society, 136 (2014) 978-985.

[23] K. Strickland, E. Miner, Q. Jia, U. Tylus, N. Ramaswamy, W. Liang, M.-T. Sougrati, F. Jaouen, S. Mukerjee, Nature communications, 6 (2015).

[24] G. Wu, P. Zelenay, Accounts of Chemical Research, 46 (2013) pp 1878-1889. 
[25] Q. Jia, N. Ramaswamy, H. Hafiz, U. Tylus, K. Strickland, G. Wu, B. Barbiellini, A. Bansil, E.F. Holby, P. Zelenay, ACS Nano, 9 (2015) 12496-12505.

[26] W. Gao, D. Havas, S. Gupta, Q. Pan, N. He, H. Zhang, H.-L. Wang, G. Wu, Carbon, 102 (2016) 346-356.

[27] G. Wu, K.L. More, P. Xu, H.-L. Wang, M. Ferrandon, A.J. Kropf, D.J. Myers, S. Ma, P. Zelenay, Chem. Commun., 49 (2013) 3291-3293.

[28] G. Wu, M.A. Nelson, N.H. Mack, S. Ma, P. Sekhar, F.H. Garzon, P. Zelenay, Chemical Communications, 46 (2010) 7489-7491.

[29] Q. Li, H. Pan, D. Higgins, R. Cao, G. Zhang, H. Lv, K. Wu, J. Cho, G. Wu, Small, 11 (2015) 1443-1452.

[30] G. Wu, C. Dai, D. Wang, D. Li, N. Li, Journal of Materials Chemistry, 20 (2010) 30593068 .

[31] C. Coperet, M. Chabanas, R.P. Saint-Arroman, J.M. Basset, Angewandte ChemieInternational Edition, 42 (2003) 156-181.

[32] X. Wang, J. Zhou, H. Fu, W. Li, X. Fan, G. Xin, J. Zheng, X. Li, Journal of Materials Chemistry A, 2 (2014) 14064-14070.

[33] S. Yuan, J.-L. Shui, L. Grabstanowicz, C. Chen, S. Commet, B. Reprogle, T. Xu, L. Yu, D.J. Liu, Angewandte Chemie-International Edition, 52 (2013) 8349-8353.

[34] B. Gole, A.K. Bar, P.S. Mukherjee, Chemical Communications, 47 (2011) 12137-12139.

[35] D. Zhao, J.-L. Shui, C. Chen, X. Chen, B.M. Reprogle, D. Wang, D.-J. Liu, Chemical Science, 3 (2012) 3200-3205.

[36] D. Zhao, J.-L. Shui, L.R. Grabstanowicz, C. Chen, S.M. Commet, T. Xu, J. Lu, D.-J. Liu, Advanced Materials, 26 (2014) 1093-1097. 
[37] S. Ma, G.A. Goenaga, A.V. Call, D.J. Liu, Chemistry-A European Journal, 17 (2011) 20632067.

[38] G. Goenaga, S. Ma, S. Yuan, D.-J. Liu, ECS Transactions, 33 (2010) 579-586.

[39] J. Xu, S. Li, J. Tan, Y. Wang, G. Luo, Langmuir, 22 (2006) 7943-7946.

[40] W. Liu, D. Sun, C. Li, Q. Liu, J. Xu, Journal of Colloid and Interface Science, 303 (2006) $557-563$.

[41] G. Wu, G. Cui, D. Li, P.-K. Shen, N. Li, Journal of Materials Chemistry, 19 (2009) 65816589.

[42] X. Wang, Y. Ke, H. Pan, K. Ma, Q. Xiao, G. Wu, M.T. Swihart, ACS Catalysis, 5 (2015) $2534-2540$.

[43] P. Su, H. Xiao, J. Zhao, Y. Yao, Z. Shao, C. Li, Q. Yang, Chemical Science, 4 (2013) 29412946.

[44] T. Yamashita, P. Hayes, Applied Surface Science, 254 (2008) 2441-2449.

[45] S. Poulin, R. França, L. Moreau-Bélanger, E. Sacher, The Journal of Physical Chemistry C, 114 (2010) 10711-10718.

[46] S.J. Rettig, A. Storr, D.A. Summers, R.C. Thompson, J. Trotter, Journal of the American Chemical Society, 119 (1997) 8675-8680.

[47] S.J. Rettig, V. Sanchez, A. Storr, R.C. Thompson, J. Trotter, Journal of the Chemical Society, Dalton Transactions, (2000) 3931-3937.

[48] J. Tian, A. Morozan, M.T. Sougrati, M. Lefevre, R. Chenitz, J.-P. Dodelet, D. Jones, F. Jaouen, Angewandte Chemie-International Edition, 52 (2013) 6867-6870.

[49] H. Tang, H. Yin, J. Wang, N. Yang, D. Wang, Z. Tang, Angewandte Chemie-International Edition, 52 (2013) 5585-5589. 
[50] M.L. Xiao, J.B. Zhu, L.G. Feng, C.P. Liu, W. Xing, Advanced Materials, 27 (2015) 25212527.

[51] Q. Li, P. Xu, W. Gao, S. Ma, G. Zhang, R. Cao, J. Cho, H.-L. Wang, G. Wu, Advanced Materials, 26 (2014) 1378-1386.

[52] Q. Li, R. Cao, J. Cho, G. Wu, Advanced Energy Materials, 4 (2014) 1301415.

[53] Q. Li, R. Cao, J. Cho, G. Wu, Phys. Chem. Chem. Phys., 16 (2014) 13568 - 13582.

[54] Q. Li, G. Wu, D.A. Cullen, K.L. More, N.H. Mack, H. Chung, P. Zelenay, ACS Catalysis, 4 (2014) 3193-3200.

[55] X. Wang, Q. Li, H. Pan, Y. Lin, Y. Ke, H. Sheng, M.T. Swihart, G. Wu, Nanoscale, 7 (2015) 20290-20298.

[56] G. Wu, A. Santandreu, W. Kellogg, S. Gupta, O. Ogoke, H. Zhang, H.-L. Wang, L. Dai, Nano Energy, (2016) doi:10.1016/j.nanoen.2015.1012.1032.

[57] Q. He, Q. Li, S. Khene, X. Ren, A. Bueno-López, G. Wu, The Journal of Physical Chemistry C, 117 (2013) 8697-8707.

[58] J. Masa, W. Xia, M. Muhler, W. Schuhmann, Angewandte Chemie International Edition, 54 (2015) 10102-10120.

[59] F. Jaouen, J.-P. Dodelet, The Journal of Physical Chemistry C, 113 (2009) 15422-15432.

[60] A. Bonakdarpour, M. Lefevre, R. Yang, F. Jaouen, T. Dahn, J.-P. Dodelet, J.R. Dahn, Electrochemical and Solid State Letters, 11 (2008) B105-B108.

[61] F. Jaouen, The Journal of Physical Chemistry C, 113 (2009) 15433-15443.

[62] T. Sugawara, N. Kawashima, T.N. Murakami, Journal of Power Sources, 196 (2011) 26152620. 
[63] U.I. Kramm, M. Lefèvre, P. Bogdanoff, D. Schmeißer, J.-P. Dodelet, The Journal of Physical Chemistry Letters, 5 (2014) 3750-3756.

[64] J. Zhou, P.N. Duchesne, Y. Hu, J. Wang, P. Zhang, Y. Li, T. Regier, H. Dai, Physical Chemistry Chemical Physics, 16 (2014) 15787-15791.

[65] J.G. Abdominal ImagingSpeight, Lange's Handbook of Chemistry, 16th Edition, 16 ed., Mc Graw-Hill, London, 2005.

[66] F. Reichel, J.K. Clegg, K. Gloe, K. Gloe, J.J. Weigand, J.K. Reynolds, C.-G. Li, J.R. Aldrich-Wright, C.J. Kepert, L.F. Lindoy, H.-C. Yao, F. Li, Inorganic Chemistry, 53 (2014) 688-690. 
Table of Content:
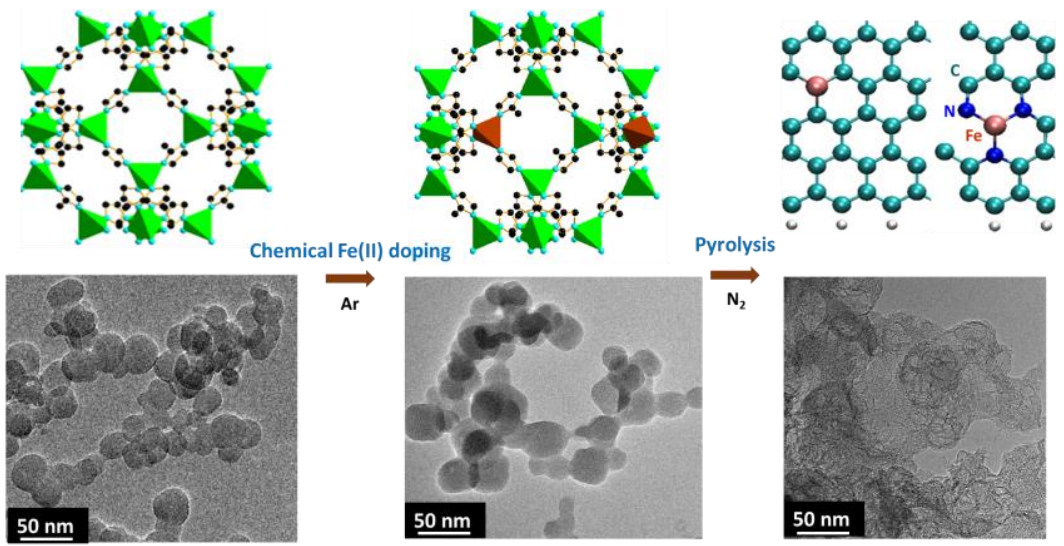

ZIF-8

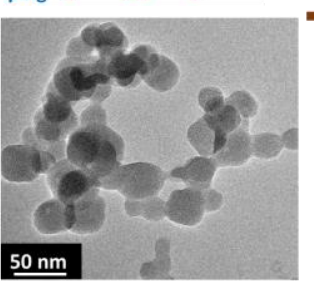

Fe-doped ZIF-8
$\overrightarrow{\mathrm{N}_{2}}$

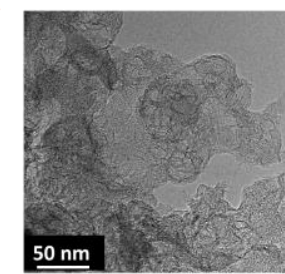

Highly dispersed Fe sites in nitrogen-doped carbon 


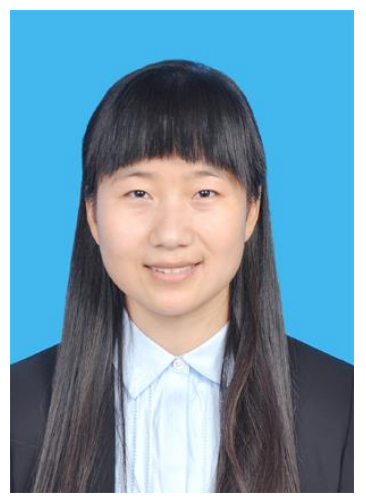

\section{Author photos and short bios}

Xiaojuan Wang received B.S. degree in Physics from Lanzhou University, China in 2011. She was a visitor scholar at University at buffalo, the State University of New York in April to July, 2016. She is currently a direct promoted PhD student in Prof. Xingguo Li's group. Her research is focused on non-precious metal catalysts for electrocatalytic oxygen reduction reaction.

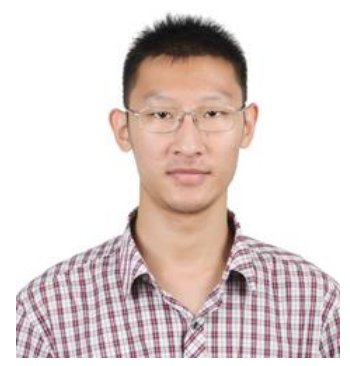

Hanguang Zhang obtained his bachelor degree in biochemical engineering at Sichuan University in 2013. He has studied synthesis of polymeric nanomaterials during his master period, and then focused on developing carbon materials for energy storage and conversion as a Ph.D student at the University at Buffalo. Now his research interest is to synthesize three-dimensional porous carbon materials for energy conversion and storage.

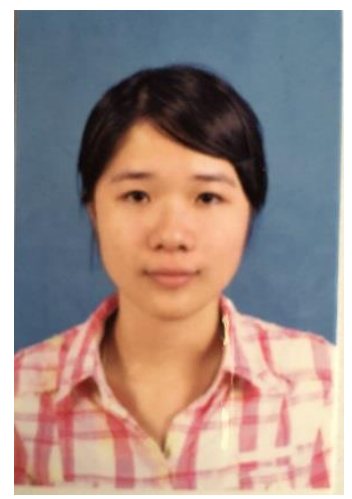

Honghong Lin is an undergraduate student, majoring in Chemistry in Peking University. Her research focuses on non-precious metal catalysts for electrocatalytic oxygen reduction reaction. 


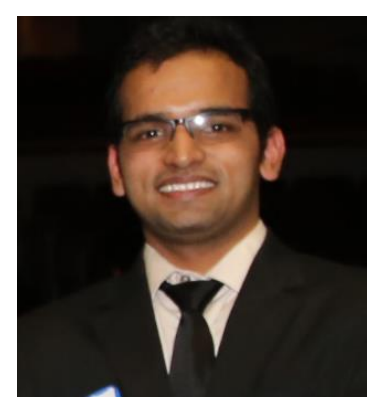

Shiva Gupta is a Ph.D. Student in the Department of Chemical and Biological Engineering at the University at Buffalo, SUNY. He obtained his B.S. from India Institute of Technology, Banaras Hindu University, Varanasi, India in 2014. His Ph.D. research project is the development of bifunctional peroviskite oxide oxygen catalysts for energy conversion.

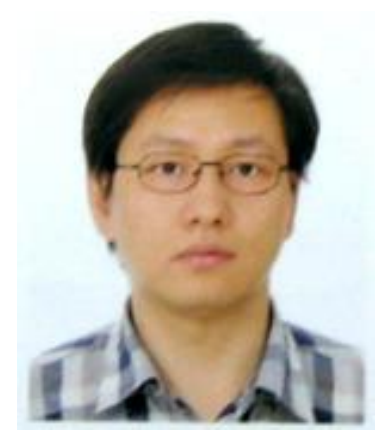

Cheng Wang, PhD supervisor, the head of hydrogen energy and fuel cell group in INET of Tsinghua University, born in Nov 1974 in Sichuan, Received PhD in 2003 in Tsinghua University. Till now, Dr. Wang has leaded more than ten research projects on fuel cell technologies, published 3 monographs and more than 90 papers in international journals, and possessed 56 invention patents

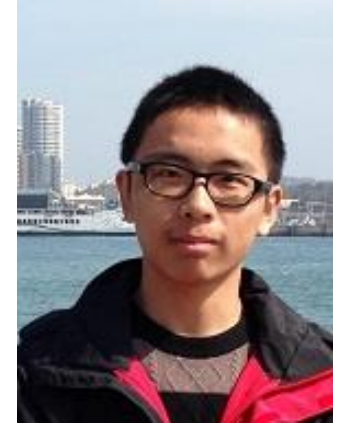

Zixu Tao is an undergraduate student, majoring in Chemistry at Peking University. His research focuses on non-precious metal catalysts for electrocatalytic oxygen reduction reaction. 


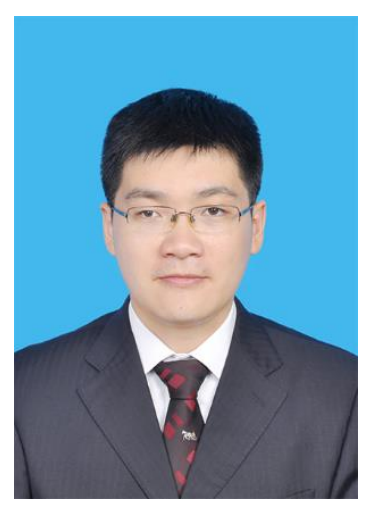

He Fu received B.S. degree in Chemistry from Peking University, China in 2011. He is currently a direct promoted PhD student in Prof. Xingguo Li's group. His research is focused on materials for hydrogen storage and hydrogen generation.

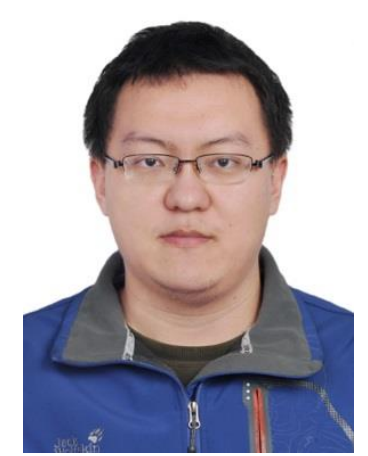

Teng Wang received B.S. degree in Chemistry from Peking University, China in 2013. He is currently a direct promoted PhD student in Prof. Xingguo Li's group. His research is focused on noblemetal-free catalysts for electrochemical hydrogen production.

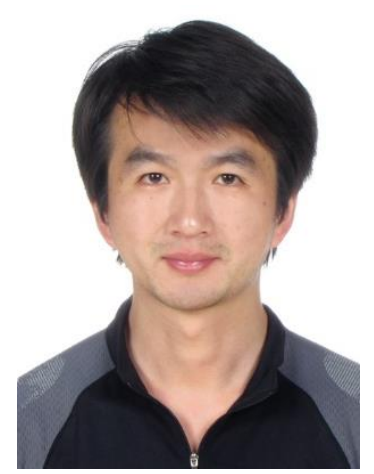

Jie Zheng received his Ph.D. degree from Peking University, China in 2009 and from Eindhoven University of Technology, the Netherlands in 2010. He is now an associate professor in College of Chemistry and Molecular Engineering, Peking University, China. His research is focused on inorganic materials for hydrogen storage/generation, batteries and fuel cells. 


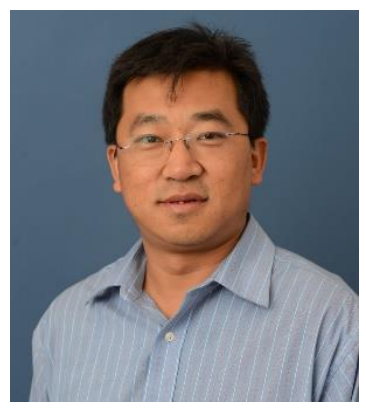

Gang $\mathbf{W u}$ is an Assistant Professor in the Department of Chemical and Biological Engineering at the University at Buffalo (UB), SUNY since August 2014. Prior to joining UB, he was a staff scientist at Los Alamos National Laboratory (LANL) since May of 2010. He completed his Ph.D. studies at the Harbin Institute of Technology in 2004 followed by postdoctoral trainings at Tsinghua University (2004-2006), the University of South Carolina (2006-2008), and LANL (2008-2010). His research focuses on functional materials and catalysts for electrochemical energy storage and conversion.

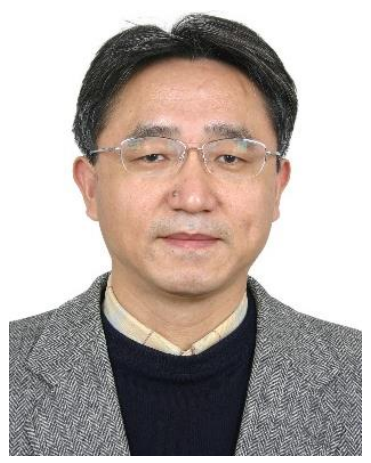

Xingguo Li received his Ph.D. degree from Tohoku University, Japan in 1990. He became a professor in College of Chemistry and Molecular Engineering, Peking University, China since 2000. His research covers hydrogen storage/generation materials, lithium ion batteries and plasma processing of nanomaterials 